C entre for

$\triangle$ boriginal

E conomic

- olicy

R esearch

Discussion Paper

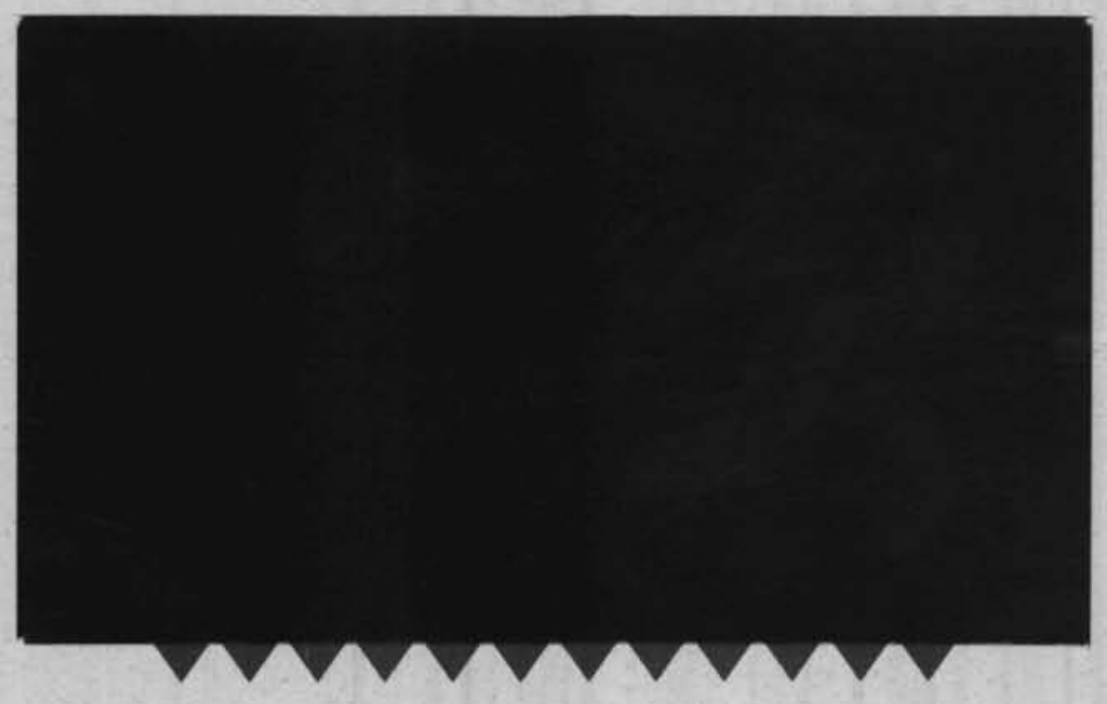


Industry segregation among employed Aborigines and Torres Strait Islanders

\section{J. Taylor}

No.22/1992

ISSN 1036-1774

ISBN $07315 \quad 13657$ 


\section{SERIES NOTE}

The Centre for Aboriginal Economic Policy Research (CAEPR) was established in March 1990 under an agreement between the Australian National University and the Commonwealth of Australia (Aboriginal and Torres Strait Islander Commission). In accordance with the Agreement, CAEPR operates as an independent research unit within the University's Faculty of Arts. CAEPR's principle objectives are to undertake research with the following aims:

- to investigate issues relating to Aboriginal employment and unemployment;

- to identify and analyse the factors affecting Aboriginal participation in the labour force; and

- to assist in the development of government strategies aimed at raising the level of Aboriginal participation in the labour force and at the stimulation of Aboriginal economic development.

The Director of the Centre is responsible to the Vice-Chancellor of the ANU and receives assistance in formulating the Centre's research agenda from an Advisory Committee consisting of senior ANU academics nominated by the Vice-Chancellor and Aboriginal representatives nominated by the Chief Executive Officer of the Aboriginal and Torres Strait Islander Commission and the Secretary of the Department of Employment, Education and Training.

CAEPR DISCUSSION PAPERS are intended as a forum for the dissemination of refereed papers on research that falls within the CAEPR ambit. These papers are produced for discussion and comment within the research community and Aboriginal affairs policy arena. Copies of discussion papers are available from Bibliotech, ANUTECH Pty Ltd, GPO Box 4, Canberra, ACT, 2601 (Phone: 062492479 FAX 06257 5088).

\section{As with all CAEPR publications, the views expressed in this DISCUSSION PAPER are those of the author(s) and do not reflect an official CAEPR position.}

Jon Altman

Director, CAEPR

Australian National University 


\section{ABSTRACT}

This paper describes the detailed industry composition of the Aboriginal and Torres Strait Islander workforce and measures the extent to which it differs from that of the rest of the workforce. For this purpose, 1986 Census data on industry division and class of employment are used and inter- and intra-industry segregation indexes are calculated. This reveals for the first time the precise industry mix which characterises the Aboriginal labour market. At the broad level of industry divisions, the degree of employment segregation between Aborigines, Islanders and others in the workforce appears to have decreased over time, although problems exist in deriving a satisfactory index to measure temporal changes in segregation. However, at the more disaggregated intraindustry level, using data for a single census year, clear patterns of relative employment concentration and exclusion in particular industry classes are in evidence. These patterns are discussed for male and female Aborigines and Islanders in each industry class with the conclusion that the bulk of Aboriginal and Islander employment is supported by a very narrow industry base which is dependent to a large extent on public sector expenditure.

\section{Acknowledgements}

Thanks are due to Jon Altman, Anne Daly and Diane Smith for their comments on an early draft of this paper and Bruce Illingworth of the Australian Bureau of Statistics for providing the detailed industry of employment tables. I would also like to thank Hilary Bek and Linda Allen for compiling the detailed industry data base.

Dr John Taylor is Senior Research Fellow, Centre for Aboriginal Economic Policy Research, Faculty of Arts, the Australian National University. 

Recent discussion has pointed to the likely existence of an Aboriginal labour market which operates separately from the rest of the labour market (Altman and Daly 1992; Taylor 1991: 74). Leaving aside the fact that Aborigines and Torres Strait Islanders display a greater tendency than other members of the labour force to be either unemployed or in low skill jobs (Daly 1991), the most apparent feature of the Aboriginal labour market is a growing concentration of employment in industries located within (or at least driven by) the public sector (Altman and Daly 1992). While the trend generally in the labour market over the past two decades has been away from employment in primary and secondary industries towards employment in service industries, the shift in this direction has been more marked among Aborigines and Islanders owing to a substantial loss of agricultural employment and a concomitant growth of employment allied to the task of servicing the Aboriginal population.

This redeployment of labour has emerged in response to supply and demand factors that are relatively unique to the Aboriginal and Islander workforce. These have been summarised by Altman and Daly (1992) and include, on the supply side, locational factors stressing remote and rural residence as well as the likely preference of Aboriginal and Islander people for particular types of employment. On the demand side, the attitudes of the wider society about what work is appropriate for Aborigines have also been influential. If supply-side factors are the major source of industry segregation, then the outcomes may be considered optimal from an Aboriginal and Islander perspective with implications for targeting employment policy. If, on the other hand, industry segregation reflects racial discrimination in the mainstream labour market or the effects of poor human capital endowment in the competition for jobs, then the issue becomes a matter which policy may seek to redress.

Whatever the processes at work, it would indeed be surprising to find Aborigines and Islanders employed in particular industries in exactly the same proportion as other workers given the degree of variation between them and the rest of the population in cultural attributes, demographic structure, place of residence, community size, and socioeconomic status. Assuming this to be the case, the question is to what extent does such a difference exist and what specific industry concentrations and shortfalls are responsible for producing this difference? In short, what does the industry composition of the aggregate Aboriginal and Islander labour market look like? To answer this question, detailed 1986 Census data on industry class of employment are used in order to highlight those particular industries in which Aborigines and Islanders are either overor under-represented when compared with the rest of the Australian workforce. 


\section{Methodology}

In a statistical sense, segregation refers to the degree of difference in the pattern of proportional distribution between two otherwise similar sets of data. A relative measure of such difference is provided by a wide range of segregation indices and one commonly used in studies of labour force segregation, the Duncan Index (Duncan and Duncan 1955), is applied here. This is calculated by summing the absolute differences between the per cent of all Aborigines and/or Islanders and all other workers employed in different industries and dividing the answer by two. For example, using hypothetical data showing the percentage of Aborigines and others employed in three industries:

\section{Aborigines employed (per cent)}

Industry A

Industry B

Industry $\mathrm{C}$

Total
Non-Aborigines employed (per cent)
Absolute difference

In this case, the Duncan Index of industrial segregation would equal 95/2 $=47.5$ per cent. In other words, almost half of Aboriginal workers (or non-Aboriginal workers) would have to change their industry of employment in order to eliminate any racial difference in the statistical distributions.

\section{Changes in broad industry segregation, 1971-86}

In order to measure changes in industry segregation over time, the Duncan Index has been calculated for the 12 broad Australian Bureau of Statistics (ABS) industry divisions as revealed by successive censuses between 1971 and $1986^{1}$ (Table 1). Also shown are the differences between the percentages of Aboriginal and Islander workers and other Australians employed in each industry, with minus signs indicating that the Aboriginal and Islander proportion is greater. Thus, agriculture accounted for 24.3 per cent of employed Aborigines and Islanders in 1971 but only 7.3 per cent of all other workers. Subtracting the Aboriginal and Islander proportion from that of other workers produces a differential in the proportions of -17.0 . In other words, the proportion of Aborigines and Islanders employed in agriculture in 1971 was greater than the proportion of other workers in the same industry by 17 percentage points. By 1986, the gap between the two proportions had 
narrowed substantially with Aboriginal and Islander employment in the industry ahead by only 1.5 percentage points.

Notwithstanding the lower than expected Duncan Index for $1976^{2}$, it appears from the overall reduction in the Index that the degree of industrial segregation between Aborigines, Torres Strait Islanders and other Australians has declined at a steady rate since 1971. In statistical terms, this means that more than one third of Aborigines and Islanders in 1971 would have been required to change their industry of employment to achieve an industry profile equivalent to that of other Australians. By 1986 , the same effect would have been achieved if just over one fifth of Aboriginal and Islander employees had relocated their industry of employment.

Table 1. Differentials in employment distribution between Aborigines and Torres Strait Islanders and other Australians by industry of employment 1971-1986.

\begin{tabular}{lrrrr} 
& \multicolumn{4}{c}{ Difference in per cent employed } \\
Industry division & 1971 & 1976 & 1981 & 1986 \\
\hline Agriculture & & & & \\
Mining & -17.0 & -4.7 & -4.1 & -1.5 \\
Manufacturing & -1.1 & -0.4 & -4.1 & -1.5 \\
Electricity, water \& gas & 11.5 & 5.2 & 9.1 & 6.2 \\
Construction & 1.0 & 0.5 & 0.6 & 0.3 \\
Wholesale, retail trade & -2.2 & -3.6 & 1.1 & 0.6 \\
Transport \& storage & 12.8 & 8.3 & 10.9 & 9.3 \\
Communication & 1.8 & 0.1 & -0.3 & -0.8 \\
Finance, prop. \& bus. serv. & 1.2 & 0.9 & 0.9 & 0.5 \\
Public admin \& defence & 5.8 & 4.3 & 6.3 & 6.3 \\
Community services & 1.7 & -3.9 & -4.8 & -6.1 \\
Recreational \& pers. serv. & -15.1 & -1.9 & -7.1 & -11.2 \\
& 1.3 & 0.8 & 1.6 & 0.6 \\
Duncan Index & & & & \\
& 37.6 & 20.1 & 30.5 & 22.8
\end{tabular}

Examination of the differences between the two groups in the proportions employed in each industry division reveals some of the labour market shifts responsible for this trend towards less segregation. As already noted, the main features include a narrowing of the difference in the proportions employed in agriculture owing to substantial job losses among Aborigines and Islanders in this industry (Altman and Daly 1992). In addition, despite a doubling in the number of Aborigines and Islanders employed in community services, the proportional increase in such employment has lagged behind that recorded for all other workers. This 
has also occurred in wholesale and retail industries. At the same time, non-Aboriginal and Islander workers have been shed in large numbers from manufacturing with the effect of reducing their relative predominance in this industry.

The overall balance of these relative shifts in employment has resulted in greater similarity between the two groups in terms of their general industry profiles. Consequently, the degree to which Aborigines and Islanders were collectively segregated in particular industry divisions in 1986 is less than might have been expected, although some difference is apparent between Aborigines and Islanders in this regard. The Duncan Index of industrial segregation is 24.9 for Aborigines in 1986 with almost no difference apparent between males and females (25.9 and 25.7 respectively). While indicating a degree of concentration in the distribution of Aboriginal employment, this result also underlines a lack of any comprehensive segregation of Aborigines into particular industries. At a general level at least, it is therefore difficult to characterise any given industry as distinctly 'Aboriginal'. As far as Torres Strait Islanders are concerned, a Duncan Index of 13.1 is even more conclusive. Despite some difference between males (15.6) and females (11.5), this indicates that Islanders as a whole are not significantly dissimilar in their distribution to the bulk of the Australian workforce, at least in terms of their broad industry category of employment.

In the context of the Federal Government's quest for equality in employment status between Aborigines, Islanders and all other Australians these results would appear, at first glance, to be encouraging particularly if the trend towards reduced segregation were to continue. It would also seem that the notion of a separate labour market existing for Aboriginal people outside of (or within) the wider labour market is less convincing now than in the past. However, before drawing any firm conclusions along these lines a degree of caution is due. Leaving aside doubts over the ability of the Duncan Index to adequately measure changes in segregation over time (Karmel and Maclachlan 1988), analysis at the broad industry level can mislead owing to a capacity of the Index to obscure concentrations which may be present in intra-industry employment patterns. It is conceivable, for example, that the proportions of employed Aborigines or Islanders found in each broad industry division may be similar to that for other Australians, while at the same time being heavily concentrated in one or a few individual industry classes within each division. For example, although the proportion of Aborigines employed in the agricultural industry is virtually identical to that of other Australians ( 7.8 per cent and 5.8 per cent respectively) almost half of the Aborigines employed (47.5 per cent) are found in just two agricultural industry classes out of a possible 42 (meat cattle and 
agriculture undefined). Clearly, with this index, the degree of segregation is contingent partly on the level of detail used in the analysis.

\section{Intra-industry segregation}

In order to examine the extent of segregation between Aborigines, Torres Strait Islanders and other Australians at the intra-industry level, detailed industry class of employment tables for these three groups were derived from the 1986 Census for both males and females. Using these finegrained data, the Duncan Index was calculated for each industry division and the results are presented in Table $2 .{ }^{3}$ It is clear that a significant degree of segregation exists in up to half of the 12 industry divisions while certain industries, such as those involving ubiquitous public utilities like electricity, water and gas supply, have noticeably little segregation. At the same time, the extent of segregation in each industry is influenced

\section{Table 2. Intra-industry Duncan Indexes for Aboriginal and Torres Strait Islander employed males and females.}

Industry division

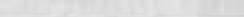

Aborigines

Agriculture

Mining

Manufacturing

Electricity, water \& gas

Construction

Wholesale \& retail trade

Transport

Finance, property \& business serv.

Public admin. \& defence

Community services

Recreational \& personal services

Torres Strait Islanders

Agriculture

Mining

Manufacturing

Electricity, water \& gas

Construction

Wholesale \& retail trade

Transport

Finance, property \& business serv.

Public admin. \& defence

Community services

Recreational \& personal services
Males

Duncan Index

Females

Total 
by gender and differs also between Aborigines and Torres Strait Islanders.

As far as differences between Aborigines and Islanders in their respective patterns of industry segregation are concerned, these are notable in only four industries - mining, manufacturing, public administration and community services. The first three of these all show a substantially greater degree of segregation among Torres Strait Islanders, while in community service industries Aborigines display greater segregation than their Islander counterparts. In all other industries, the degree of segregation displayed by Aborigines and Torres Strait Islanders is broadly similar. As for any differential along gender lines among Aborigines, these only occur in public administration and community services in which males are more segregated than females. Among Torres Strait Islanders, females are more heavily segregated in the mining industry and higher segregation indexes for males appear in public administration and community service industries.

The particular employment concentrations responsible for producing high segregation indexes can be identified by isolating those specific industries in which Aborigines and Islanders are heavily over-represented when compared to other workers and, conversely, those in which they are clearly under-represented. This is done in the process of calculating the Duncan Index by measuring the direction and degree of difference between the percentages of Aboriginal, Islander and other workers employed in each individual industry. The average of the differences in each industry provides a yardstick against which notable concentrations of employment may be identified (as illustrated, by way of example, for males employed in agricultural industries in Figure 1). The average difference in the proportions of Aboriginal and non-Aboriginal males employed in each agricultural industry class is 3.2 percentage points. In this case, five industry classes stand out as having differentials that are greater than this. In four of these, agriculture undefined, cereals, sheep, and milk cattle, Aboriginal males are under-represented, that is, nonAborigines are proportionally more prominent than Aborigines. In the industry class, meat cattle, the opposite is the case and Aborigines are considerably over-represented. The actual industry class data is too detailed to reproduce in full here. Instead, similar patterns of over- and under-representation to those identified in Figure 1 are discussed for each industry in turn. 
Figure 1. Differentials in percentage of Aboriginal and nonAboriginal males employed in agricultural industry classes.

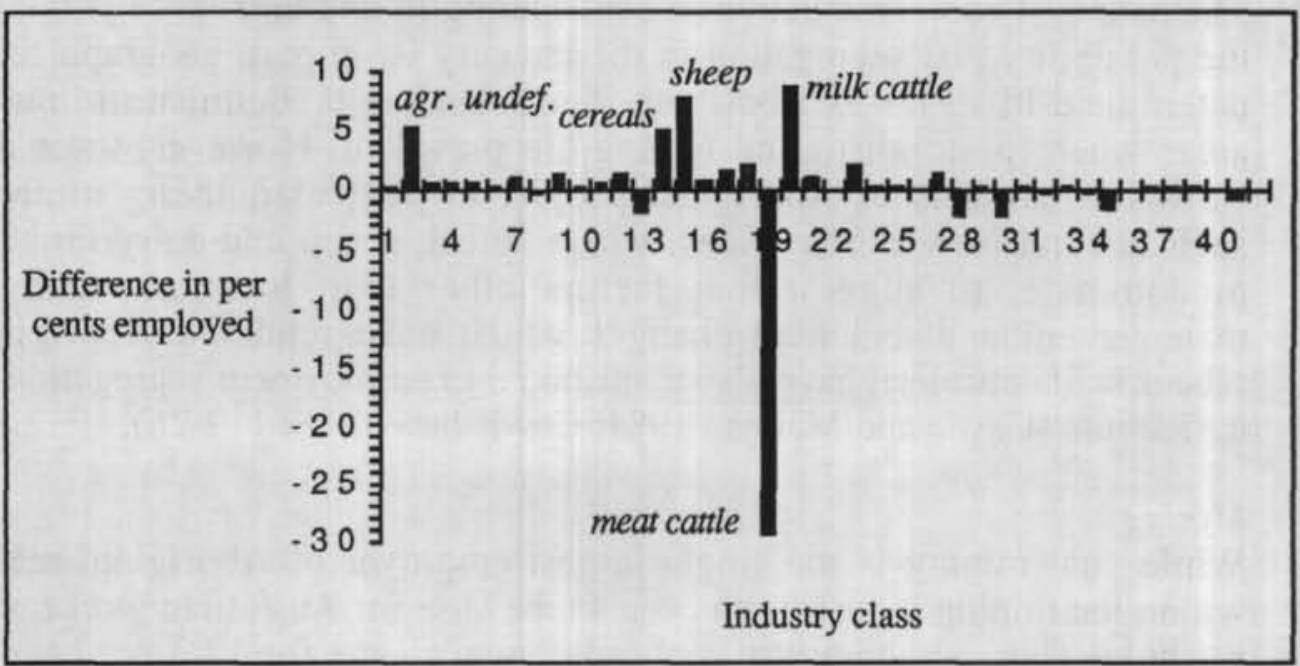

\section{Agriculture}

The employment pattern of Aboriginal and Islander people as a whole within agriculture is significantly different from that of other Australian workers owing to their over-concentration in a few industries and their relative absence from others. For example, more than one third (37 per cent) of Aboriginal males employed in agriculture are concentrated in just one industry class (meat cattle) out of a possible 42 . This reflects the historical association of Aboriginal people with the pastoral industry in remote parts of Australia. At the same time, they are significantly underrepresented in the cereal grains, sheep and dairy industries when compared with non-Aboriginal workers. A similar pattern is observed for Aboriginal females who also show a tendency to concentrate in nonclassified agricultural industries which includes a whole range of activities from beekeeping to horse breeding. Torres Strait Islanders are also noted for their relative absence from cereal and sheep farming but unlike Aborigines they are also under-represented in the pastoral industry. By contrast, both male and female Islanders show a clear concentration in the plantation fruit industry, which comprises tropical as opposed to temperate fruits, and undefined forms of fishing industry such as fishing for trochus shell, turtle and crabs. Male Islanders are also heavily represented in ocean and coastal fishing, oyster farming and the rock lobster industry.

In all other agricultural pursuits, Aborigines and Islanders are represented in almost equal proportion to other Australian workers. However, the balance of their over- and under-representation in a few 
specific activities is such that employment segregation within the agricultural industry as a whole is quite marked, as indicated by the Duncan Indexes of 41.3 for Aborigines and 34.8 for Islanders (Table 2). The nature of economic activities contributing to this imbalance points to the possibility that segregation in the industry is, in part, geographically determined in so far as Aborigines and Islanders predominate in many areas where pastoralism and fishing are prevalent. However, there are sufficient numbers of Aboriginal people, in particular, living in areas such as rural New South Wales, where cereal, sheep and dairy farming predominate, to suggest that factors other than location, such as management and technical changes which have rendered Aboriginal labour skills obsolete, have also contributed to employment segregation in agriculture (Castle and Mangan 1984; Cowlishaw 1988: 119-26).

\section{Mining}

While coal mining is the single largest employer of Aboriginal males within the mining industry, this is also the case for Australian workers as a whole. Thus, although the coal industry accounts for 17.2 per cent of Aboriginal males employed in mining, this is clearly an underrepresentation when compared with the figure of 36 per cent recorded for other Australians and results in a fairly high Duncan Index of 33.3. Some degree of concentration is apparent for Aboriginal males in gold mining and non-metallic minerals which includes industries such as gypsum, diamond and opal mining. In all other areas of mining employment, Aborigines do not differ greatly in proportion from the rest of the workforce. The one exception is the notable absence of Aboriginal females from mineral exploration although their low overall numbers in mining employment (49) reduce the significance of this observation. Torres Strait Islanders are also under-represented in the coal industry, although not to the same extent as Aborigines. Their segregation in the mining sector is due predominantly to a concentration of employment in bauxite mining which accounts for 28.4 per cent of all Islander males engaged and reflects the impact of mining operations at Weipa in Far North Queensland.

These figures highlight the care that needs to be taken when drawing conclusions from the Duncan Index. Given that the size of the Aboriginal and Islander workforce differs from the size of the rest of workforce by a factor of one hundred, comparable or divergent distributions may be achieved by relatively small numbers of Aborigines and Islanders. For example, the fact that the proportion of Aboriginal males in the mining industry who are employed in uranium mining (1.3 per cent) is comparable to the equivalent proportion for non-Aborigines $(0.7$ per cent), does not suggest that uranium mining employs large numbers of Aboriginal males. On the contrary, the 1986 Census recorded only nine 
Aboriginal employees in this industry despite the presence of two large uranium mines on Aboriginal land at the time.

\section{Manufacturing}

Given the large number of individual industries classified as manufacturing (224), it is not surprising to find Aborigines and Islanders absent from some of these. Aboriginal males, for example, are employed across a wide range of manufacturing industries (mostly in small numbers) and are absent from only 35 individual classes (15.6 per cent of the total). Aboriginal females, on the other hand, are absent from 78 manufacturing industry classes ( 34.8 per cent) while the figures for Torres Strait Islanders are higher still (38.8 per cent for males and 66.5 per cent for females). By comparison, non-Aboriginal and Islander workers are represented in all classes of manufacturing industry. This lack of Aboriginal and Islander employment across large areas of manufacturing industry accounts for the high Duncan Indexes particularly in respect of Torres Strait Islanders. As with agriculture, it is likely that location in areas remote from the main bases of manufacturing accounts for much of this segregation. At the same time, one-third of all Aboriginal and Islander workers are resident in major urban areas where the bulk of manufacturing industry is found.

Both Aborigines and Islanders show a degree of employment concentration most notably in the meat industry which essentially comprises abattoir operations, followed some way behind by the processed food industry, and the wood and wood products industry. Conversely, they are significantly under-represented in the motor vehicle industry, the iron and steel industry, and printing and publishing.

Electricity, water and gas

As might be expected in an industry concerned with the widespread provision of public utilities, the gap in employment distribution between Aborigines, Islanders and others is relatively minor as indicated by very low Duncan Indexes. However, such variation as does occur in this industry is due to an almost wholesale tendency for Aborigines and Islanders to be over-employed in the water supply industry as opposed to the electricity or gas industries. Whether this reflects different levels of skill required by these industries is not known. At the same time, it may be significant that Aboriginal councils and associations frequently assume responsibility for the task of delivering and supervising water supplies to Aboriginal settlements.

\section{Construction}

There is little difference in the proportions of Aborigines and Islanders employed and the proportions of other workers employed across a wide range of construction industries such as bricklaying, concreting and 
tiling. What segregation does occur within this industry, however, is due to a clear distinction between employment in trades-based and non-tradesbased industries. For example, both male and female Aborigines and Islanders are over-represented in road and bridge construction and relatively under-employed in plumbing and electrical work. Once again, apart from different skill levels, this may reflect the involvement of Aboriginal councils in providing work through the maintenance of local road systems in and around Aboriginal settlements.

\section{Wholesale and retail trade}

For the most part, Aborigines and Islanders are distributed across the 95 individual wholesale and retail industries in much the same proportions as other workers. At the same time, some clear patterns of segregation are apparent within the industry. For example, grocers shops (community stores) are by far the single most important employer for all Aboriginal and Islander workers in the retail industry accounting for 13 per cent of Aboriginal males, 18 per cent of Islander males and up to one-third of all females. Some degree of over-representation in smash repairs and new motor vehicle dealers is also apparent among males. Set against this is a pattern of male under-employment in business machine retailers, machine equipment wholesalers and pharmacies, while females are most noted for their relative absence from employment in department stores and women's wear stores as well as pharmacies.

\section{Transport}

Relatively high Duncan Indexes are recorded for this industry, particularly for Torres Strait Islanders, although their pattern of employment distribution is similar to that for Aborigines. Males, for example, are heavily concentrated in rail transport with this industry accounting for 59.6 per cent of Aboriginal male transport workers and 58 per cent of their Torres Strait Islander counterparts. Aboriginal and Islander females are also over-represented in this industry with the latter also prominent in non-scheduled air transport and services to water transport. Aboriginal and Islander males show some degree of absence from the short bus and tramway industry, while Aboriginal and Islander females are much less likely than other females to be employed in domestic and international air transport and travel agency services.

\section{Finance, property and business services}

It is perhaps ironic that the very industry least perceived as being associated with Aboriginal and Islander employment is the one in which a fairly wide spread of employment across individual industry classes is achieved. Several industries in this group display a distinct niche for Aborigines and Islanders but at the same time there are other industries from which they are clearly excluded leading to considerable polarisation of intra-industry employment. Those industries with a surfeit of 
Aborigines and Islanders reflect the impact of land rights and the growth of localised bureaucracies servicing the Aboriginal and Islander population. These include land trusts, mutual funds, residential property operators and legal services. Over-representation in cleaning services and plant hire may also be associated with employment in small scale Aboriginal and Islander enterprises especially in rural communities. Those industries with a deficit of Aborigines and Islanders are equally distinctive being urban-based and generally large corporate organisations. These include trading banks, savings banks, real estate agents, insurance services, accounting services, architectural services, market and business consultancies, data processing and the advertising industry.

\section{Public administration and defence}

It is to be expected that employment segregation in this industry would be relatively low given the probability that jobs in the public sector are most likely to reflect affirmative action and equity policies of government. While the Duncan Index for Aborigines as a whole is comparatively low this is largely due to a very low index for females as the index for males is much higher. The index for Torres Strait Islanders clearly points to a degree of segregation within this industry, although a similar pattern of gender difference to that of Aborigines is apparent. Such segregation as does exist in this industry division is due to a straightforward imbalance between under-employment in defence industries and over-representation in local government, although Aboriginal females differ from this as they are most concentrated in federal government administration.

\section{Community services}

Out of 51 industries within this category, two alone (welfare, charitable services and community organisations) account for the bulk of community service employment among Aboriginal and Torres Strait Islander males (50.2 per cent and 40.1 per cent respectively). This reflects the crucial role played by Aboriginal and Islander organisations in providing a focus of local employment in many communities (Johnston 1991: 92-5). It is also indicative of government policies of Aboriginalisation and localisation as well as the comparative advantage favouring Aboriginal and Islander employees in industries which often require culturally-derived skills. The level of male concentration in these two industries is exacerbated by a relative lack of employment in primary and secondary schools, universities and the police force. As other Australian males are more evenly distributed throughout the community service industry, the inbalance in Aboriginal and Islander employment is reflected in high Duncan Indexes.

Despite the fact that Aboriginal and Islander females show less overall segregation than males they also show a tendency to concentrate in welfare and charitable services and community organisations as well as in 
pre-schools, and community health centres. Welfare and charitable services include such things as alcohol rehabilitation centres, refuge operations, family welfare agencies and childminding services. As with their male counterparts, a pattern of employment concentration in localised community-based industries is again apparent. This is emphasised by the fact that Aboriginal and Islander females are relatively under-employed, when compared with other females, in larger more institutionalised community service industries including hospitals, nursing homes, medicine, primary and secondary schools. Despite the fact that hospitals and primary schools, in particular, are significant employers of Aboriginal and Islander females, the health and education industries employ other females in much greater proportion.

\section{Recreation, personal and other services}

While most industries in this category employ similar proportions of Aborigines, Islanders and other workers, a few stand out as exceptional and create a polarity in employment distribution. On the one side, accommodation is clearly an industry which provides an important source of employment for Aborigines and Islanders. Much of this employment is through Aboriginal Hostels Ltd, a Commonwealth owned company which employs more than 400 Aboriginal and Islander staff. Another industry in which Aboriginal males, in particular, are over-represented is parks and zoological gardens which most likely reflects their involvement in Commonwealth and State park authorities. At the other extreme, Aborigines and Islanders show a distinct pattern of under-employment in cafes and restaurants when compared with other Australian workers. This is consistent with empirical evidence that Aborigines frequently lack the skills or the inclination for employment in hospitality industries (Kesteven 1987; Altman 1988).

\section{Policy implications}

Despite a trend over time towards statistical convergence in the employment distribution of Aborigines, Islanders and other Australian workers across the 12 broad industry divisions, it is clear from the analysis of more disaggregated data that the bulk of Aboriginal and Islander employment is concentrated in very few industry classes. At the intra-industry level, clear patterns of employment concentration and exclusion are in evidence. Out of 612 individual industry classes identified in the Australian Standard Industrial Classification (ASIC), as few as 24 of these, in rank order of numbers employed, account for 50 per cent of all Aborigines employed while 38 industry classes account for half of all Torres Strait Islanders in employment. The equivalent number for the rest of the Australian workforce is 57 industries. To emphasise this disparity further, the top ten employing industries account for 38.4 
per cent of all Aborigines in the workforce, 31.6 per cent of all Torres Strait Islanders and only 18.9 per cent of all other workers. It would be fair to say, however, that such a variation in the spread of employment across individual industry classes is to be expected given the difference in the size of the groups being compared. In this context, perhaps the most notable feature of these figures is the greater spread apparent among Torres Strait Islanders compared to Aborigines despite their much fewer numbers.

Analysis of those industries in which Aborigines and Islanders are overrepresented shows these to be predominantly within the public sector domain whether funded directly by government or via a community organisation servicing the Aboriginal population. Thus, industries such as rail transport, water supply, road building, retail grocers, legal aid, residential property operations, accommodation, local adminstration, welfare and community organisations all employ a much greater proportion of Aborigines and Islanders than other Australian workers. Exceptions to this pattern include primary industries such as pastoralism, fishing and bauxite mining which reflects a greater Aboriginal and Islander presence in remote areas where such activities predominate. Conversely, Aborigines and Islanders are noted for their underemployment in many areas of the finance and business service industry, specialised construction industries, coal mining, cereal, sheep and dairy farming, major manufacturing industry, air transport, large retail and wholesale operations, and the health and education industries. A notable feature of the pattern of employment by industry class is the lack of any significant gender difference. Thus, unlike the situation among the workforce as a whole, Aboriginal and Islander females are concentrated in many of the same industries as their male counterparts.

One drawback from this overview is the absence of data which reflects the involvement of Aborigines and Islanders in economic activities that are unrecorded by the Census, most notably in the arts and crafts industry. In the 1986 Census, 15 Aboriginal and Islander people were identified as artists, 20 as painters and sculptors and 24 as designers and illustrators. This official count of the numbers engaged in the arts and crafts industry represents a gross underestimate when compared with the figure of 4,838 practising artists identified by the Review of the Aboriginal arts and crafts industry in 1988 (Altman 1989: 34). Clearly, unrecorded industry participation on this scale has the potential to substantially alter descriptions of the Aboriginal labour market derived from census data. At the same time, just how much informal economic activity among the total population is also overlooked by the census is a moot point. A further limitation is that the results presented here are cross-sectional and refer only to the situation in 1986. However, future comparison with 1991 Census results will allow for an analysis of change 
over time to test the validity of assertions that application of the Aboriginal Employment Development Program (AEDP) during the intercensal period is likely to have increased industry segregation (Altman and Daly 1992). Future research could also usefully explore variations in the Duncan Index and associated patterns of industry concentration according to place of residence criteria. It is likely, for example, that variations in industry segregation exist between those Aborigines and Islanders employed in major urban areas and those employed in rural localities.

It is clear from the above that Aboriginal and Islander employment is dependent upon a very narrow industry base supported to a large extent by public expenditure. While this is hardly a novel discovery, the data presented here reveal for the first time the precise industry mix which characterises the Aboriginal labour market. Of equal importance, from a policy perspective, is the identification of those specific industry classes in which Aborigines and Islanders are over- and under-employed compared to other Australian workers. To further understanding of the Aboriginal labour market, the question that remains to be answered is why this imbalance occurs. In some industries, such as agriculture, it appears that employment concentrations are in part geographically and historically driven while in other industries, such as business, community and personal services, they may be more culturally derived. Underrepresentation in certain industries is more difficult to explain and may be the consequence of demand-side or supply-side factors operating within the Aboriginal labour market. On the surface, industries that under-employ Aborigines and Islanders appear to share high human capital requirements, such as medicine, education, accounting, and various trades-based industries. Equally, however, there are many examples, such as cafes and restaurants, department stores, and banks, where this is less likely to be the case and where factors such as discrimination or personal choice may be more responsible. In some industries, therefore, the general thrust of the Aboriginal Education Policy towards upgrading Aboriginal and Islander skills may be beneficial in bringing about greater equality in employment distribution. In other cases, however, attempts at raising the level of human capital may prove ineffective owing to Aboriginal and Islander preferences in the labour market.

The Duncan Index as used here provides a measure of the scale of the task involved in achieving the AEDP goal of statistical equality in employment distribution. Clearly, if such a goal were to be met then, ipso facto, a much greater spread across industries would be required. The crucial question is, what level of industry balance should be struck? If an equal distribution is sought across the 12 broad industry divisions then, as noted, this is already very close for Torres Strait Islanders and not much further removed for Aborigines. If, on the other hand, equality is sought 
in much more specific arenas of employment, at the level of individual classes of industry, then a much more substantial redistribution is required targetting those industries which significantly under-employ Aborigines and Islanders.

This begs the question of whether statistical equality, in the sense described here for industry of employment, is a useful or even appropriate yardstick against which to measure the enhancement of Aboriginal and Islander employment status. If such equality were to exist, would this imply a transfer of employment into activities which may be perceived as assimilationist for many Aboriginal and Islander people? What of those industries where equal proportions are already employed or where over-employment exists - should Aboriginal and Islander advancement in these areas be stifled to allow progress in other industries where under-employment exists? Wouldn't a more balanced distribution of employment by industry imply much greater Aboriginal and Islander involvement in mainstream labour markets and a population distribution more in favour of large urban places? Given that this would require substantial labour migration (Taylor 1991), is this feasible or even desirable?

Leaving aside these wider policy questions, it is also important to remember that limitations exist in the application of statistical measurement to social issues. For example, very small numbers of Aborigines, and particularly Islanders, employed in a given industry can constitute an equal proportion to the rest of the workforce. Thus, while statistical balance or equality may be achieved, the actual impact in terms of the number of jobs involved will be far from equal given the difference in order of magnitude between the size of the groups being compared. Likewise, the achievement of equal industry distribution would almost certainly involve a re-ordering of employment profiles contrary to the aspirations of many Aborigines and Islanders. For many communities, whether rural or urban-based, participation in a limited range of industries may be precisely in keeping with employment aspirations. In remote areas, it may be all that can be achieved anyway given the small size of many communities. This implies a need for flexibility in policy with acknowledgement that statistical equality may not always be achievable or desired.

Disaggregated analysis of relative employment status, in this case by industry class, highlights the fact that attempts to achieve statistical equality may not only be assimilationist and over-ambitious (Sanders 1991) but at times may border on the absurd. At the same time, use of a segregation index does enable identification of the particular industry divisions and classes of industry that would impact most on the relative employment status of Aboriginal and Islander people were they to decline 
in economic importance. For example, any decline in the fortunes of the pastoral and fishing industries and many publicly-funded service industries would have a deleterious effect. By contrast, it is interesting to note the boost given to rail transport in the recent Keating economic statement as both Aborigines and Islanders are significantly concentrated in this particular transport industry class and are likely to improve their employment prospects as a result. On the other hand, if industries which under-employ Aborigines and Islanders experience an increase in their share of overall employment, which seems likely to be the case as the workforce becomes more highly skilled (Department of Employment Education and Training 1991), then the Index will provide a measure of how effective industry-based employment programs, such as those with Commonwealth statutory authorities like Telecom, the Australian Broadcasting Commission and Australia Post, and in the private sector with major airlines, banks and hotel groups, have been in ensuring that those Aborigines and Islanders who want to participate in the mainstream labour market do not fall further behind in this pursuit.

\section{Notes}

1. Karmel and Maclachlan (1988) suggest a revised Index which keeps the overall balance between different groups in the workforce constant over time. While it is recognised that changes in the relative size of the Aboriginal and Islander workforce between 1971 and 1986 may undermine the interpretation of change in the Duncan Index, the fact that Aborigines and Islanders constitute such a small proportion of the total workforce also complicates use of the revised Index.

2. The 1976 Census was based on a 50 per cent sample of all completed Census forms in all areas except the Northern Territory. This has raised doubts over the validity of disaggregated statistics for Aborigines and Torres Strait Islanders, placing a particular question mark over the reliability of time series data. (For a fuller discussion of these problems see Altman and Gaminiratne 1992.)

3. It is important to note that intra-industry Indexes are not comparable owing to the tendency of the Index to increase with the detail of industrial classification (Karmel and Maclachlan 1988).

\section{References}

Altman, J.C. 1988. Aborigines, Tourism and Development: The Northern Territory Experience. Darwin: North Australia Research Unit.

Altman, J.C. (Chairman) 1989. The Aboriginal Arts and Crafts Industry: Report of the Review Committee. Canberra: Australian Government Publishing Service.

Altman J. C. and Daly, A. 1992. Do Fluctuations in the Australian Macroeconomy Influence Aboriginal Employment Status?, CAEPR Discussion Paper No. 21. Canberra: Centre for Aboriginal Economic Policy Research, Australian National University. 
Altman, J.C. and Gaminiratne, K.H.W. 1992. Establishing Trends in ATSIC Regional Council Populations Using Census Data: A Cautionary Note, CAEPR Discussion Paper No. 20. Canberra: Centre for Aboriginal Economic Policy Research, Australian National University.

Castle, R. and Mangan, J. (eds) 1984. Unemployment in the Eighties. Melbourne: Longman Cheshire.

Cowlishaw, G. 1988. Black White or Brindle: Race in Rural Australia. Cambridge: Cambridge University Press.

Daly, A. 1991. The Participation of Aboriginal People in the Australian Labour Market, CAEPR Discussion Paper No. 6. Canberra: Centre for Aboriginal Economic Policy Research, Australian National University.

Department of Employment, Education and Training 1991. Australia's Workforce in the Year 2001. Canberra: Australian Government Publishing Service.

Duncan, O.D. and Duncan, B. 1955. 'A methodological analysis of segregation indexes', American Sociological Review, 20: 210-17.

Johnston, E. 1991. Review of the Training for Aboriginals Program. Report to the Ministers for Employment, Education and Training, and Aboriginal Affairs. Canberra: Aussie Print.

Karmel, T. and Maclachlan, M. 1988. 'Occupational sex segregation - increasing or decreasing?', The Economic Record, 64 (September): 187-95.

Kesteven, S. 1987. Aborigines in the Tourist Industry, East Kimberley Working Paper No. 14. Canberra: Centre for Resource and Environmental Studies, Australian National University.

Sanders, W. 1991. 'Destined to fail: the Hawke Government's pursuit of statistical equality in employment and income status between Aborigines and other Australians by the year 2000 (or, a cautionary tale involving the new managerialism and social justice strategies)', Australian Aboriginal Studies, 1991/2: 13-18.

Taylor, J. 1991. 'Aboriginal labour migration for employment: the evidence', in J.C. Altman (ed.) Aboriginal Employment Equity by the Year 2000. Canberra: Centre for Aboriginal Economic Policy Research, Australian National University. 



\section{CENTRE FOR ABORIGINAL ECONOMIC POLICY RESEARCH (CAEPR) DISCUSSION PAPERS:}

1. 'From exclusion to dependence: Aborigines and the welfare state in Australia' by J.C. Altman and W. Sanders (March 1991).

2. 'Geographic variations in the economic status of Aboriginal people: a preliminary investigation' by H. Tesfaghiorghis (March 1991).

3. 'Aboriginal socio-economic status: are there any evident changes?' by H. Tesfaghiorghis and J.C. Altman (March 1991).

4. 'Indigenous economic development in the Torres Strait: possibilities and limitations' by W.S. Arthur (March 1991).

5. 'The CDEP scheme: administrative and policy issues' by J.C. Altman and W. Sanders (September 1991).

6. 'The participation of Aboriginal people in the Australian labour market' by A.E. Daly (September 1991).

7. 'The impact of welfare on the economic status of Aboriginal women' by A.E. Daly (September 1991).

8. 'Geographic location and Aboriginal economic status: a census-based analysis of outstations in Australia's Northern Territory' by J. Taylor (September 1991).

9. 'Aboriginal expenditure patterns: an analysis of empirical data and its policy implications' by D.E. Smith (September 1991).

10. 'Toward an Aboriginal household expenditure survey: conceptual, methodological and cultural considerations' by D.E. Smith (September 1991).

11. 'Aboriginal economic status by ATSIC regions: analyses of 1986 Census data' by H. Tesfaghiorghis (October 1991).

12. 'Appropriate income support for Aboriginal Australians: options for the 1990 s' by J.C. Altman (October 1991). 
13. 'Aboriginal unemployment statistics: policy implications of the divergence between official and case study data' by D.E. Smith (October 1991).

14. 'Living off the land in national parks: issues for Aboriginal Australians' by J.C. Altman and L.M. Allen (October 1991).

15. 'Funding allocations to Aboriginal people: the Western Australia case' by W.S. Arthur (December 1991).

16. 'The employment of Aboriginal Australians in the labour market' by A.E. Daly (December 1991).

17. 'Spatial mobility of working age Aborigines in settled and remote Australia: a preliminary analysis by J. Taylor (December 1991).

18. 'Social indicators of the Aboriginal population of Australia' by A. Gray and H. Tesfaghiorghis (December 1991).

19. 'Estimating the reliance of Aboriginal Australians on welfare: some policy implications' by J.C. Altman and D.E. Smith (March 1992).

20. 'Establishing trends in ATSIC regional council populations using census data: a cautionary note' by J.C. Altman and K.H.W. Gaminiratne (March 1992).

21. 'Do fluctuations in the Australian macroeconomy influence Aboriginal employment status?' by J.C. Altman and A.E. Daly (March 1992).

22. 'Industry segregation among employed Aborigines and Torres Strait Islanders' by J. Taylor (March 1992). 

